\title{
Evaluation of Atrial Conduction Times, Epicardial Fat Thickness and Carotid Intima-Media Thickness in Patients With Ankylosing Spondylitis
}

\author{
Sabri Onur ÇAĞLAR, ${ }^{1}$ İsmail BOYRAZ, ${ }^{2}$ Fatma ERDEM,,${ }^{1}$ Selma YAZICI, ${ }^{2}$ Hilal ÇAĞLAR, ${ }^{2}$ \\ Bünyamin KOÇ, ${ }^{2}$ Emrah ÇAĞLAR, ${ }^{3}$ Mehmet YAZICI $^{1}$ \\ ${ }^{1}$ Department of Cardiology, Abant İzet Baysal Training and Research Hospital, Bolu, Turkey \\ ${ }^{2}$ Department of Physical Medicine and Rehabilitation, Medical Faculty of Abant İzet Baysal University, Bolu, Turkey \\ ${ }^{3}$ Department of Radiology, Abant İzet Baysal Training and Research Hospital, Bolu, Turkey
}

\begin{abstract}
Objectives: This study aims to determine the relationship between atrial electromechanical delay (EMD), carotid intima-media thickness (CIMT), and epicardial fat thickness (EFT) in ankylosing spondylitis (AS), which has a complicated inflammatory nature.

Patients and methods: The study population included 42 consecutive patients with AS ( 28 males, 14 females; mean age $39.3 \pm 8.5$ years; range 22 to 60 years) and 40 healthy subjects as controls ( 24 males, 16 females; mean age $37.2 \pm 8.7$ years; range 22 to 60 years) ( $p>0.05$ ). All patients underwent a standard tissue Doppler echocardiography to assess the left ventricular diastolic dysfunction, atrial EMD, CIMT, and EFT. All values were compared between the groups.

Results: Interatrial $(29.5 \pm 5.8 \mathrm{~ms}$ vs. $17.9 \pm 5.3 \mathrm{~ms})$ left and right intraatrial EMD $(18.2 \pm 4.6 \mathrm{~ms}$ and $11.7 \pm 3.5 \mathrm{~ms}$ vs. $11.9 \pm 3.2 \mathrm{~ms}$ and $7.1 \pm 3.2 \mathrm{~ms}$, respectively) intervals were longer in AS patients than in healthy controls (all $\mathrm{p}<0.001)$. Left and right CIMT $(0.50 \pm 0.11 \mathrm{~mm}$ and $0.44 \pm 0.06 \mathrm{~mm}$ vs. $0.51 \pm 0.11 \mathrm{~mm}$ and $0.43 \pm 0.04 \mathrm{~mm}$, respectively) and EFT $(0.73 \pm 0.15 \mathrm{~cm}$ and $0.63 \pm 0.07 \mathrm{~cm})$ values were higher in AS patients than in healthy controls (all $\mathrm{p}<0.01$ ).

Conclusion: To our best knowledge, this is the first report evaluating the atrial EMD, CIMT, and EFT values together in AS patients. As indicators of cardiovascular involvement, all parameters were higher in AS patients.

Keywords: Ankylosing spondylitis; atrial conduction time; carotid intima-media thickness; epicardial fat thickness.
\end{abstract}

Ankylosing spondylitis (AS) is a chronic inflammatory disease with involvement of the sacroiliac joint and spine. It is noted that AS patients may additionally have cardiovascular system involvement. The prevalence of cardiovascular disease appears to reach $64 \% .^{1}$ Though the underlying cause of the increase in cardiovascular pathologies has not been fully explained, it is thought that the chronic inflammatory process and autoimmunity play a part in this course. ${ }^{2}$

Atrial fibrillation (AF) is the most common arrhythmia type in the population. It is related to increased cardiac morbidity and mortality. ${ }^{3}$
Pathophysiological mechanism leading to AF is electrical and/or structural remodeling developing in the atrium. ${ }^{4}$ Studies have shown that AS patients have a tendency to develop AF. ${ }^{5}$ Previous studies have reported that chronic inflammation eases the development of AF. However, there is still no consensus on whether AS can trigger atrial arrhythmias. ${ }^{6,7}$ It is especially important to determine predisposing factors for AF development in this patient group.

Tissue Doppler echocardiography is a beneficial diagnostic tool used to determine atrial conduction times. ${ }^{8}$ Using this technique, electromechanical 
delay (EMD) intervals are obtained for different areas of the atrium. Studies have proposed that many electrophysiological parameters including inter- and intraatrial EMD are predisposing factors for the development of AF.,10

Atherosclerosis is the most frequent cause of coronary artery disease (CAD). It affects the medium- and large-diameter arteries in the body, in addition to the coronary arteries. Endothelial dysfunction and increased intima-media thickness are early findings of atherosclerosis. ${ }^{11}$ Due to its easy application and non-invasive nature, carotid intima-media thickness (CIMT) is widely used with the aim of identifying subclinical atherosclerosis. ${ }^{12}$ Epicardial fat thickness (EFT), forming as a result of visceral fat tissue accumulating around the heart, is a new cardiometabolic risk predictor. ${ }^{13}$ In close contact with the myocardium, EFT works like a type of endocrine organ. ${ }^{14}$ However, there appears to be no clear data in terms of atherosclerosis development related to EFT.12,15 Accordingly, in this study, we aimed to determine the relationship between atrial EMD, CIMT, and EFT in AS, which has a complicated inflammatory nature.

\section{PATIENTS AND METHODS}

A total of 42 patients (28 males, 14 females; mean age $39.3 \pm 8.5$ years; range 22 to 60 years) and 40 healthy controls (24 males, 16 females; mean age $37.2 \pm 8.7$ years; range 22 to 60 years) were included in the study. Control group was similar to the study group in terms of age and sex (both $p>0.05$ ). All participants were selected from the Departments of Physical Medicine and Rehabilitation and Cardiology of Abant Izzet Baysal University. They were diagnosed as AS on the basis of Assessment of SpondyloArthritis International Society criteria ${ }^{5,12}$ between December 2014 and April 2015. This study was approved by our Institutional Ethics Committee. A written informed consent was obtained from each patient. The study was conducted in accordance with the principles of the Declaration of Helsinki.

Subjects with hypertension, diabetes, hypercholesterolemia, renal dysfunction, hypertriglyceridemia, connective tissue disease, and other inflammatory rheumatic diseases were excluded. All patients' electrocardiographies (ECG) were in sinus rhythm and patients were not taking any cardiac medications. We collected all blood specimens after 10 hour fasting. All participants were advised not to take heavy exercise and not to consume coffee, tea, energy drinks or alcohol before the examination. Serum lipid levels, complete blood count, erythrocyte sedimentation rate, C-reactive protein level, and hepatic/renal function tests were measured.

Echocardiographic examinations of all individuals were performed by the same commercially available machine (Epiq7, Philips, 2-4 $\mathrm{MHz}$ phased array transducer) (Koninklijke Philips N.V., 2004-2016). During the evaluation of echocardiography, three-lead ECG was recorded simultaneously. M-mode measurements were applied according to criteria of American Society of Echocardiography. ${ }^{16}$ Left atrium diameter, aortic root, ascendant aorta, left ventricular end-diastolic and end-systolic diameters were measured. Left ventricular ejection fraction was evaluated by Simpson's rule. ${ }^{17}$ Pulsed-wave mitral flow velocities were evaluated from apical fourchamber view by inserting a sample volume on mitral leaflet tips. Mitral early diastolic velocity $(\mathrm{E}, \mathrm{cm} / \mathrm{s})$, late diastolic velocity $(\mathrm{A}, \mathrm{cm} / \mathrm{s})$, and $\mathrm{E} / \mathrm{A}$ ratio were calculated.

Atrial electromechanical coupling is the time interval from the onset of $\mathrm{P}$ wave to the late diastolic wave on ECG. It was obtained from lateral mitral annulus, septal mitral annulus, and right ventricular tricuspid annulus and called as PA lateral, PA septum, and PA tricuspid, respectively. Interatrial EMD was measured by the difference between PA lateral and PA tricuspid. Left intraatrial EMD was measured by the difference between PA lateral and PA septum, and finally, right intraatrial EMD was measured by the difference between PA septum and PA tricuspid. ${ }^{18,19}$ An average measurement was achieved after obtaining these values three times.

Epicardial fat thickness was measured by using echocardiography device (Epiq7, Philips, 2-4 $\mathrm{MHz}$ phased array transducer). We obtained EFT thickness in parasternal long axis window, from the right ventricular free wall at the end of the thickest location diastole.

The radiologist was blinded and CIMT was performed after a 10 minute rest, while patients 
were lying on their backs with their heads aligned 20 to $30^{\circ}$ in the opposite direction. A radiologist obtained images using a Philips ClearVue 350 model Doppler ultrasonography device (Logiq S7 Expert, GE Healthcare, Wauwatosa, WI, USA) with $12-\mathrm{MHz}$ linear transducer. Carotid intima-media thickness measurement was carried out when optimal longitudinal images could be obtained appropriately, $1 \mathrm{~cm}$ proximally from the common carotid artery bifurcation level and behind the posterior wall. The borders of the carotid artery lumen and adventitia were observed like double lines. Measurements were obtained between the echogenic line (intima) facing the lumen and the echogenic lines of the adventitia on the outside. We calculated the mean of the results obtained from three different points in both carotid arteries.

\section{Statistical analysis}

IBM SPSS software version 20.0 (IBM Corporation, Armonk, NY, USA) was used for statistical analysis. Continuous variables were presented as mean \pm standard deviation while categorical variables were presented as $n$ or ratio. Numerical variables of the groups were distributed normally, and variances were equal. Chi-square test was performed to compare categorical variables between the groups. Since the baseline demographics, laboratory and echocardiographic values were normally distributed; Student's t-test was performed to compare these parameters. $\mathrm{P}<0.05$ was considered statistically significant.

\section{RESULTS}

According to the basic clinical and demographic characteristics, both groups were similar with regards to age, body mass index, heart rate, systolic blood pressure, diastolic blood pressure, smoking status, fasting glucose, and other biochemical parameters (Table 1).

Comparison of the baseline echocardiographic values are shown in Table 2. Interatrial $(29.5 \pm 5.8 \mathrm{~ms}$ vs. $17.9 \pm 5.3 \mathrm{~ms})$ left and right intraatrial EMD $(18.2 \pm 4.6 \mathrm{~ms}$ and $11.7 \pm 3.5 \mathrm{~ms}$ vs. $11.9 \pm 3.2 \mathrm{~ms}$ and $7.1 \pm 3.2 \mathrm{~ms}$, respectively) intervals were longer in AS patients than in healthy controls (all $\mathrm{p}<0.001$ ). Left and right CIMT $(0.50 \pm 0.11 \mathrm{~mm}$ and $0.44 \pm 0.06$ $\mathrm{mm}$ vs. $0.51 \pm 0.11 \mathrm{~mm}$ and $0.43 \pm 0.04 \mathrm{~mm}$, respectively) and EFT $(0.73 \pm 0.15 \mathrm{~cm}$ and $0.63 \pm 0.07 \mathrm{~cm})$ values were higher in AS patients than in healthy controls (all $p<0.01$ ). Left atrium diameter was higher in patients with AS than healthy controls $(p=0.012)$. Epicardial fat thickness values and all measurements regarding atrial electromechanical coupling findings were higher in AS patients (Table 3). In addition, both CIMT values were higher in the patient group (Table 3).

\begin{tabular}{|c|c|c|c|c|c|c|c|}
\hline \multirow[t]{2}{*}{ Characteristic } & \multicolumn{3}{|c|}{ AS patient group $(n=42)$} & \multicolumn{3}{|c|}{ Control group $(\mathrm{n}=40)$} & \multirow[b]{2}{*}{$p$} \\
\hline & $\mathrm{n}$ & $\%$ & Mean $\pm \mathrm{SD}$ & $\mathrm{n}$ & $\%$ & Mean \pm SD & \\
\hline Age (years) & & & $39.4 \pm 8.5$ & & & $37.3 \pm 8.7$ & 0.267 \\
\hline Sex & & & & & & & 0.436 \\
\hline Male & 28 & & & 24 & & & \\
\hline Female & 14 & & & 16 & & & \\
\hline Body mass index $\left(\mathrm{kg} / \mathrm{m}^{2}\right)$ & & & $23.9 \pm 7.9$ & & & $21.9 \pm 5.6$ & 0.423 \\
\hline Smokers & & 28.5 & & & 27.5 & & 0.789 \\
\hline Heart rate (beats/min) & & & $75.8 \pm 7.9$ & & & $73.2 \pm 8.5$ & 0.639 \\
\hline Systolic blood pressure $(\mathrm{mmHg})$ & & & $112.3 \pm 9.1$ & & & $115.4 \pm 8.3$ & 0.351 \\
\hline Diastolic blood pressure (mmHg) & & & $73.2 \pm 6.1$ & & & $75.1 \pm 6.2$ & 0.542 \\
\hline Glucose (mg/dL) & & & $89.3 \pm 7.1$ & & & $88.7 \pm 6.9$ & 0.784 \\
\hline White blood cells $\left(\mathrm{x} 10^{3} \mathrm{U} / \mathrm{L}\right)$ & & & $8.0 \pm 1.8$ & & & $7.8 \pm 1.7$ & 0.647 \\
\hline Hemoglobin $(\mathrm{g} / \mathrm{dL})$ & & & $14.0 \pm 1.8$ & & & $14.2 \pm 1.67$ & 0.703 \\
\hline Platelets $\left(\times 10^{6} / \mu \mathrm{L}\right)$ & & & $8.8 \pm 3.3$ & & & $8.3 \pm 3.2$ & 0.322 \\
\hline Urea $(\mathrm{mg} / \mathrm{dL})$ & & & $28.4 \pm 9.3$ & & & $29.2 \pm 9.3$ & 0.715 \\
\hline Creatinine (mg/dL) & & & $0.9 \pm 0.2$ & & & $0.9 \pm 0.2$ & 0.725 \\
\hline Triglyceride (mg/dL) & & & $124 \pm 66$ & & & $130 \pm 33$ & 0.741 \\
\hline Total cholesterol (mg/dL) & & & $175 \pm 38$ & & & $179 \pm 34$ & 0.754 \\
\hline
\end{tabular}


Table 2. Echocardiographic features of study subjects

\begin{tabular}{|c|c|c|c|}
\hline \multirow[t]{2}{*}{ Variable } & AS patient group $(n=42)$ & Control group $(n=40)$ & \multirow[b]{2}{*}{$p$} \\
\hline & Mean \pm SD & Mean \pm SD & \\
\hline Left ventricle ejection fraction (\%) & $66.3 \pm 5.2$ & $64.3 \pm 6.2$ & 0.107 \\
\hline Left ventricular end-diastolic diameter (mm) & $50.2 \pm 5.1$ & $49.3 \pm 4.1$ & 0.540 \\
\hline Left ventricle end-systolic diameter (mm) & $33.2 \pm 3.5$ & $31.5 \pm 3.6$ & 0.213 \\
\hline Left ventricle mass index $\left(\mathrm{g} / \mathrm{m}^{2}\right)$ & $98.5 \pm 18.6$ & $94.6 \pm 18.2$ & 0.113 \\
\hline Septum thickness (mm) & $8.9 \pm 1.2$ & $8.8 \pm 1.1$ & 0.432 \\
\hline Posterior wall thickness (mm) & $8.3 \pm 0.7$ & $8.5 \pm 0.6$ & 0.133 \\
\hline E wave $(\mathrm{cm} / \mathrm{s})$ & $81.2 \pm 17.6$ & $83.1 \pm 23.5$ & 0.102 \\
\hline A wave $(\mathrm{cm} / \mathrm{s})$ & $72.1 \pm 15.5$ & $71.6 \pm 18.3$ & 0.180 \\
\hline Left ventricle $\mathrm{E} / \mathrm{A}$ ratio & $1.14 \pm 0.13$ & $1.17 \pm 0.12$ & 0.210 \\
\hline Left atrium diameter $(\mathrm{mm})$ & $39.2 \pm 3.2$ & $33.4 \pm 4.8$ & 0.012 \\
\hline
\end{tabular}

\section{DISCUSSION}

To the best of our knowledge, this is the first study evaluating the parameters of atrial EMD, CIMT, and EFT values together in AS patients. In our study, we detected that the atrial EMD, CIMT, and EFT were increased in AS patients.

Cardiac involvement is a complication observed in AS patients. The most common occurrences are aortic root diseases and intracardiac conduction system anomalies. Increased myocardial fibrosis has been reported in AS patients. As a result, conduction system anomalies appear to be more significant compared to aortic root diseases. ${ }^{20,21}$ Atrial conduction disorders developing linked to electrophysiological and electromechanical abnormalities increase risk of AF development. ${ }^{9}$ According to recent studies, the intra- and interatrial electromechanical conduction times are higher in paroxysmal AF patients compared to a control group..$^{22,23}$
A variety of etiologic factors have been shown to cause AF including genetic susceptibility, $\mathrm{CAD}$, and cardiac toxins. ${ }^{24-26}$ Together with these findings, recent studies have identified the presence of a relationship between chronic inflammation and AF development. In AF patients, infiltration of the atrial myocardium by inflammatory cells was observed. ${ }^{27,28}$ In our study, we observed that the inter- and intraatrial conduction times were increased in the patient group. Abnormal increased activity has been shown in AS patients both in our study and previous studies. ${ }^{29-32}$ It is predicted that these patients may have high risk for the development of AF. Though there is still no clear evidence, we believe that increased incidence of AF in AS patients may be related to chronic inflammation and increased myocardial fibrosis.

Epicardial fat thickness is thought to play an important role in the pathogenesis of CAD. Epicardial fat synthesizes many biologically active

Table 3. Atrial electromechanical coupling, epicardial fat thickness, and carotid intima-media thickness results of study subjects

\begin{tabular}{|c|c|c|c|}
\hline \multirow[t]{2}{*}{ Variable } & AS patient group $(n=42)$ & \multirow{2}{*}{$\frac{\text { Control group }(n=40)}{\text { Mean } \pm \text { SD }}$} & \multirow[b]{2}{*}{$p$} \\
\hline & Mean \pm SD & & \\
\hline Atrial electromechanical coupling lateral (ms) & $68.4 \pm 12.3$ & $63.2 \pm 11.6$ & 0.05 \\
\hline Atrial electromechanical coupling septal (ms) & $55.2 \pm 10.5$ & $48.6 \pm 5.3$ & 0.001 \\
\hline Atrial electromechanical coupling tricuspid (ms) & $45.6 \pm 8.9$ & $39.2 \pm 5.8$ & $<0.001$ \\
\hline Atrial electromechanical coupling lateral-tricuspid (interatrial) (ms) & $29.5 \pm 5.8$ & $17.9 \pm 5.3$ & $<0.001$ \\
\hline Atrial electromechanical coupling lateral-septum (left intraatrial) (ms) & $18.2 \pm 4.6$ & $11.7 \pm 3.5$ & $<0.001$ \\
\hline Atrial electromechanical coupling septum-tricuspid (right intraatrial) (m & $11.9 \pm 3.2$ & $7.1 \pm 3.2$ & $<0.001$ \\
\hline Right carotid intima-media thickness $(\mathrm{mm})$ & $0.51 \pm 0.11$ & $0.43 \pm 0.04$ & $<0.001$ \\
\hline Left carotid intima-media thickness $(\mathrm{mm})$ & $0.50 \pm 0.11$ & $0.44 \pm 0.06$ & 0.008 \\
\hline Epicardial fat thickness $(\mathrm{cm})$ & $0.73 \pm 0.15$ & $0.63 \pm 0.07$ & $<0.001$ \\
\hline
\end{tabular}


materials providing modulation of the vascular smooth muscle. The paracrine effects of these materials may be linked to their being close to the adventitia and extravascular bed. ${ }^{14,33,34}$ Gastaldelli and Basta ${ }^{14}$ showed a relationship between EFT and hypertension, atherosclerosis and CAD. Again, a study including 62 hemodialysis patients identified a strong relationship between CIMT and EFT thickness. ${ }^{35}$ Nakanishi et al. ${ }^{36}$ used computed tomography to measure EFT levels and reported that patients with high levels had more coronary artery calcification. In studies by Cece et al. ${ }^{12}$ and Resorlu et al., ${ }^{37}$ CIMT values in AS patients were found to be higher than those of the control group. In our study, AS patients had increased EFT thickness with high CIMT values. Based on these findings, we may conclude that AS patients with a tendency toward increased EFT thickness should be placed in the high-risk group in terms of CAD.

The main limitation of our study is the small sample size. In addition, AS patients could have been followed-up for a longer duration to observe possible cardiac complications.

In conclusion, patients with AS have an increased risk for cardiac involvement. We demonstrated that the atrial EMD, CIMT, and EFT were increased in AS patients. These factors might lead to the development of $\mathrm{CAD}$, atherosclerosis and AF in AS patients. Therefore, AS patients should be examined by a cardiologist and undergo regular ECG and echocardiographic examinations for any cardiac involvement.

\section{Declaration of conflicting interests}

The authors declared no conflicts of interest with respect to the authorship and/or publication of this article.

\section{Funding}

The authors received no financial support for the research and/or authorship of this article.

\section{REFERENCES}

1. Takkunen J, Vuopala U, Isomäki H. Cardiomyopathy in ankylosing spondylitis. I. Medical history and results of clinical examination in a series of 55 patients. Ann Clin Res 1970;2:106-12.

2. Sherer Y, Shoenfeld Y. Mechanisms of disease: atherosclerosis in autoimmune diseases. Nat Clin
Pract Rheumatol 2006;2:99-106.

3. Turpie AG. Rivaroxaban as an oral anticoagulant for stroke prevention in atrial fibrillation. Ther Clin Risk Manag 2014;10:197-205.

4. Tang M, Zhang S, Sun Q, Huang C. Alterations in electrophysiology and tissue structure of the left atrial posterior wall in a canine model of atrial fibrillation caused by chronic atrial dilatation. Circ J 2007;71:1636-42.

5. Acar G, Sayarlioglu M, Akcay A, Sokmen A, Sokmen G, Altun B, et al. Assessment of atrial electromechanical coupling characteristics in patients with ankylosing spondylitis. Echocardiography 2009;26:549-57.

6. Kazmierczak J, Peregud-Pogorzelska M, Biernawska J, Przepiera-Bedzak H, Goracy J, Brzosko I, et al. Cardiac arrhythmias and conduction disturbances in patients with ankylosing spondylitis. Angiology 2007;58:751-6.

7. Yildirir A, Aksoyek S, Calguneri M, Aytemir K, Kabakci G, Ovunc K, et al. QT dispersion as a predictor of arrhythmic events in patients with ankylosing spondylitis. Rheumatology (Oxford) 2000;39:875-9.

8. Deniz A, Sahiner L, Aytemir K, Kaya B, Kabakci G, Tokgozoglu L, et al. Tissue Doppler echocardiography can be a useful technique to evaluate atrial conduction time. Cardiol J 2012;19:487-93.

9. Daubert JC, Pavin D, Jauvert G, Mabo P. Intra- and interatrial conduction delay: implications for cardiac pacing. Pacing Clin Electrophysiol 2004;27:507-25.

10. Acar G, Sayarlioğlu M, Akçay A, Sökmen A, Sökmen G, Yalçintaş $S$, et al. Evaluation of atrial electromechanical delay and left atrial mechanical functions in patients with rheumatoid arthritis. Turk Kardiyol Dern Ars 2009;37:447-53.

11. Kuller L, Borhani N, Furberg C, Gardin J, Manolio $\mathrm{T}$, O'Leary $\mathrm{D}$, et al. Prevalence of subclinical atherosclerosis and cardiovascular disease and association with risk factors in the Cardiovascular Health Study. Am J Epidemiol 1994;139:1164-79.

12. Cece H, Yazgan P, Karakas E, Karakas O, Demirkol A, Toru I, et al. Carotid intima-media thickness and paraoxonase activity in patients with ankylosing spondylitis. Clin Invest Med 2011;34:225.

13. Jeong JW, Jeong MH, Yun KH, Oh SK, Park EM, Kim YK, et al. Echocardiographic epicardial fat thickness and coronary artery disease. Circ J 2007;71:536-9.

14. Gastaldelli A, Basta G. Ectopic fat and cardiovascular disease: what is the link? Nutr Metab Cardiovasc Dis 2010;20:481-90.

15. Skare TL, Verceze GC, Oliveira AA, Perreto S. Carotid intima-media thickness in spondyloarthritis patients. Sao Paulo Med J 2013;131:100-5.

16. Quiñones MA, Otto CM, Stoddard M, Waggoner A, Zoghbi WA. Recommendations for quantification of Doppler echocardiography: a report from the Doppler Quantification Task Force of the Nomenclature and Standards Committee of the American Society of Echocardiography. J Am Soc Echocardiogr 
2002;15:167-84.

17. Devereux RB, Reichek N. Echocardiographic determination of left ventricular mass in man. Anatomic validation of the method. Circulation 1977;55:613-8.

18. Lang RM, Bierig M, Devereux RB, Flachskampf FA, Foster E, Pellikka PA, et al. Recommendations for chamber quantification: a report from the American Society of Echocardiography's Guidelines and Standards Committee and the Chamber Quantification Writing Group, developed in conjunction with the European Association of Echocardiography, a branch of the European Society of Cardiology. J Am Soc Echocardiogr 2005;18:1440-63.

19. Deniz A, Sahin DY, Kanadasi M, Demir M, Berk IG, Akkus $\mathrm{O}$, et al. Conduction characteristics in atrial fibrillation. Predictive value of tissue Doppler echocardiography. Herz 2014;39:137-41.

20. Bergfeldt L, Edhag O, Vallin H. Cardiac conduction disturbances, an underestimated manifestation in ankylosing spondylitis. A 25-year follow-up study of 68 patients. Acta Med Scand 1982;212:217-23.

21. Liu SM, Alexander CS. Complete heart block and aortic insufficiency in rheumatoid spondylitis. Am J Cardiol 1969;23:888-92.

22. Omi W, Nagai H, Takamura M, Okura S, Okajima $\mathrm{M}$, Furusho $\mathrm{H}$, et al. Doppler tissue analysis of atrial electromechanical coupling in paroxysmal atrial fibrillation. J Am Soc Echocardiogr 2005;18:39-44.

23. Cui QQ, Zhang W, Wang H, Sun X, Wang R, Yang HY, et al. Assessment of atrial electromechanical coupling and influential factors in nonrheumatic paroxysmal atrial fibrillation. Clin Cardiol 2008;31:74-8.

24. Darbar D, Herron KJ, Ballew JD, Jahangir A, Gersh BJ, Shen WK, et al. Familial atrial fibrillation is a genetically heterogeneous disorder. J Am Coll Cardiol 2003;41:2185-92.

25. Liberthson RR, Salisbury KW, Hutter AM Jr, DeSanctis RW. Atrial tachyarrhythmias in acute myocardial infarction. Am J Med 1976;60:956-60.

26. Ettinger PO, Wu CF, De La Cruz C Jr, Weisse AB, Ahmed SS, Regan TJ. Arrhythmias and the "Holiday Heart": alcohol-associated cardiac rhythm disorders. Am Heart J 1978;95:555-62.

27. Yao SY, Chu JM, Chen KP, Tang M, Fang PH, Wang $\mathrm{FZ}$, et al. Inflammation in lone atrial fibrillation. Clin
Cardiol 2009:32:94-8.

28. Chen MC, Chang JP, Liu WH, Yang CH, Chen YL, Tsai $\mathrm{TH}$, et al. Increased inflammatory cell infiltration in the atrial myocardium of patients with atrial fibrillation. Am J Cardiol 2008;102:861-5.

29. Bacaksiz A, Erdogan E, Tasal A, Vatankulu MA, Kul S, Sevgili E, et al. Electrocardiographic P-wave characteristics in patients with psoriasis vulgaris. Ups J Med Sci 2013;118:35-41.

30. Brunner F, Kunz A, Weber U, Kissling R. Ankylosing spondylitis and heart abnormalities: do cardiac conduction disorders, valve regurgitation and diastolic dysfunction occur more often in male patients with diagnosed ankylosing spondylitis for over 15 years than in the normal population? Clin Rheumatol 2006;25:24-9.

31. Onrat E, Demirdal S, Dursun H, Çakır T, Kilit C, Avşar A et al. A New cardiac autonomic function predictor (Heart Rate Turbulence) in patients with ankylosing spondylitis. Turk J Rheumatol 2010;25:196-200.

32. Üstün N, Kurt M, Atci N, Yağiz E, Güler H, Turhanoğlu A. Increased epicardial fat tissue is a marker of subclinic atherosclerosis in ankylosing spondylitis. Arch of Rheumatol 2014;29:267-72.

33. Szasz T, Webb RC. Perivascular adipose tissue: more than just structural support. Clin Sci (Lond) 2012;122:1-12.

34. Bachar GN, Dicker D, Kornowski R, Atar E. Epicardial adipose tissue as a predictor of coronary artery disease in asymptomatic subjects. Am $\mathrm{J}$ Cardiol 2012;110:534-8.

35. Altun B, Tasolar H, Eren N, Binnetoğlu E, Altun M, Temiz A, et al. Epicardial adipose tissue thickness in hemodialysis patients. Echocardiography 2014;31:941-6.

36. Nakanishi R, Rajani R, Cheng VY, Gransar H, Nakazato R, Shmilovich $\mathrm{H}$, et al. Increase in epicardial fat volume is associated with greater coronary artery calcification progression in subjects at intermediate risk by coronary calcium score: a serial study using noncontrast cardiac CT. Atherosclerosis 2011;218:363-8.

37. Resorlu H, Akbal A, Resorlu M, Gokmen F, Ates C, Uysal $F$, et al. Epicardial adipose tissue thickness in patients with ankylosing spondylitis. Clin Rheumatol 2015;34:295-9. 